\title{
Some considerations on the distribution pattern of the mosquito Aedes albopictus (Skuse) and the practical usefulness of the $\log (x+1)$ transformation for the field collection data
}

\author{
Kiyoshi MaKIYA* \\ Department of Medical Zoology, Nagoya University School of Medicine, \\ Shoica-ku, Nagoya 466, Japan \\ (Received: August 29, 1976)
}

\begin{abstract}
Some ecological considerations were made on the distribution pattern of egg, larval (pupal) and imaginal populations of Aedes albopictus in a cemetery area of Nagoya City, central Japan in 1972.

The mean crowding $\stackrel{*}{m})$-mean density $(m)$ relation, or $\stackrel{*}{m}=\alpha+\beta m$, was applied to the observed individual counts in order to analyze the distribution pattern of the mosquitoes of each stage. The results indicate that the basic components of the spatial distribution seem to be groups of several individuals, and that such small groups of each stage mosquito distribute aggregatively in the area.
\end{abstract}

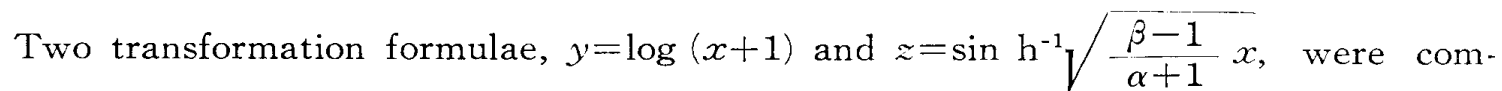
pared in their efficiencies of stabilizing variance and normalizing variate frequency distribution, with a result that the former transformation was as useful as the latter.

\section{INTRODUCTION}

In preceeding papers (Makiya, 1973, 1975), it was revealed that the distribution of mosquitoes seemed to be aggregative and to fit well to the negative binomial distribution with a common parameter $k$. And comparison was made among three methods of transformation, $\log (x+1)$ (Williams, 1937), $\log (x+k / 2)$ (Anscombe, 1948) and $\sqrt{k} \sin$ $\mathrm{h}^{-1} \sqrt{k x}$ (Beall, 1942) in their efficiencies of stabilizing variance and normalizing variate distribution and in practical usefulness. As a result, $y=\log (x+1)$ transformation was adopted because of its facility in practical use and adequate transformation efficacy.

And the Williams' mean (=antilog $\bar{y}-1$; Williams, 1937) was proved to be more suitable than the arithmetic mean in interpreting fluctuation of population size in

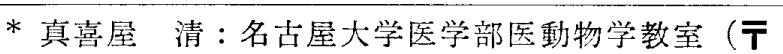
466 名古屋市炤和区鶴舞町) an area as a whole and comparing abundance of mosquitoes between sampling sites.

In the present paper, the mean crowdingmean density relation was applied to the field collection data of Aedes albopictus in a cemetery area in order to analyze the distribution pattern of the mosquito.

\section{STUdy AREA AND METHODS}

Study area, Yagoto cemetery park, is one of the largest municipal graveyards (ca. 30 ha) of Nogoya City, central Japan. Ten sections were selected randomly in the cemetery area and one stone basin was chosen in each of these sections. Larval and pupal sampling was made by ladling water out of the basins with a small dipper $(180 \mathrm{ml})$ screened with wire netting at the bottom. Two samples were taken from each basin at an interval of about three minutes. Adult mosquitoes attacking to bite the author were collected with an aspirator at 
each larval sampling station.

For the purpose of quantitative sampling of eggs, oviposition traps (ovitraps) were used. This ovitrap consisted of the cylindrical plastic jar $(5.5 \mathrm{~cm}$ in diam., $9.5 \mathrm{~cm}$ deep) wrapped with a glossy black cover, containing a cardboard paddle $(4 \times 10 \mathrm{~cm})$ for oviposition, a vial including $5 \mathrm{ml}$ of $95 \%$ ethyl acetate as attractant, and $150 \mathrm{ml}$ of tap water. Ten ovitraps were placed on the ground beneath bushes in the sampling stations. Eggs deposited on the paddle surface or sunk onto the bottom of the traps were counted under a stereomicroscope.

Sampling were made at regular intervals of about 10 days during the period from April to November 1972.

\section{RESULTS}

During the eight months of study, the total of 3,262 larvae and pupae, 1,089 adults $(\phi+\hat{o})$ and 1,403 eggs of Aedes albopictus were collected from the 10 stations.

It is necessary to know the spatial distribution pattern of the mosquito in order to clarify the population fluctuation in this cemetery area as a whole. The mean crowding $(\stackrel{*}{m})$-mean density $(m)$ relation, $\stackrel{*}{m}=$ $\alpha+\beta m$, was applied in analyzing the distribution pattern of each stage of the mosquito.

The mean crowding, i.e. the mean number of other individuals per quadrat (or sampling unit) per individual, is defined as

$$
\stackrel{*}{m}=\frac{\sum x_{i}^{2}}{\sum x_{i}}-1=m+\left(\frac{\sigma^{2}}{m}-1\right),
$$

where $x_{i}$ is the number of individuals in the $i$ th unit $(i=1,2, \cdots, n)$ and $\sigma^{2}$ the variance (Lloyd, 1967). Estimates of the mean crowding $(\stackrel{*}{x})$ were calculated using the formula, $\stackrel{*}{x}=\bar{x}+\left(\frac{s^{2}}{\bar{x}}-1\right)$, where $\stackrel{*}{x}$ and $s^{2}$ are unbi. ased estimates of $m$ and $\sigma^{2}$.

The intercept $\alpha$ of the regression, $\stackrel{*}{m}=\alpha+$ $\beta m$, is the index of basic contagion, which indicates whether a single individual or a group of individuals is the basic component of the distribution. The slope $\beta$ is the density-contagiousness coefficient which suggests how such basic components distribute in their habitat at different densities (Iwao, 1968).

In Fig. 1 are shown the $\stackrel{*}{x}-\bar{x}$ relations of the egg, larval (pupal) and imaginal populations, and their $\alpha, \beta$ values are listed in
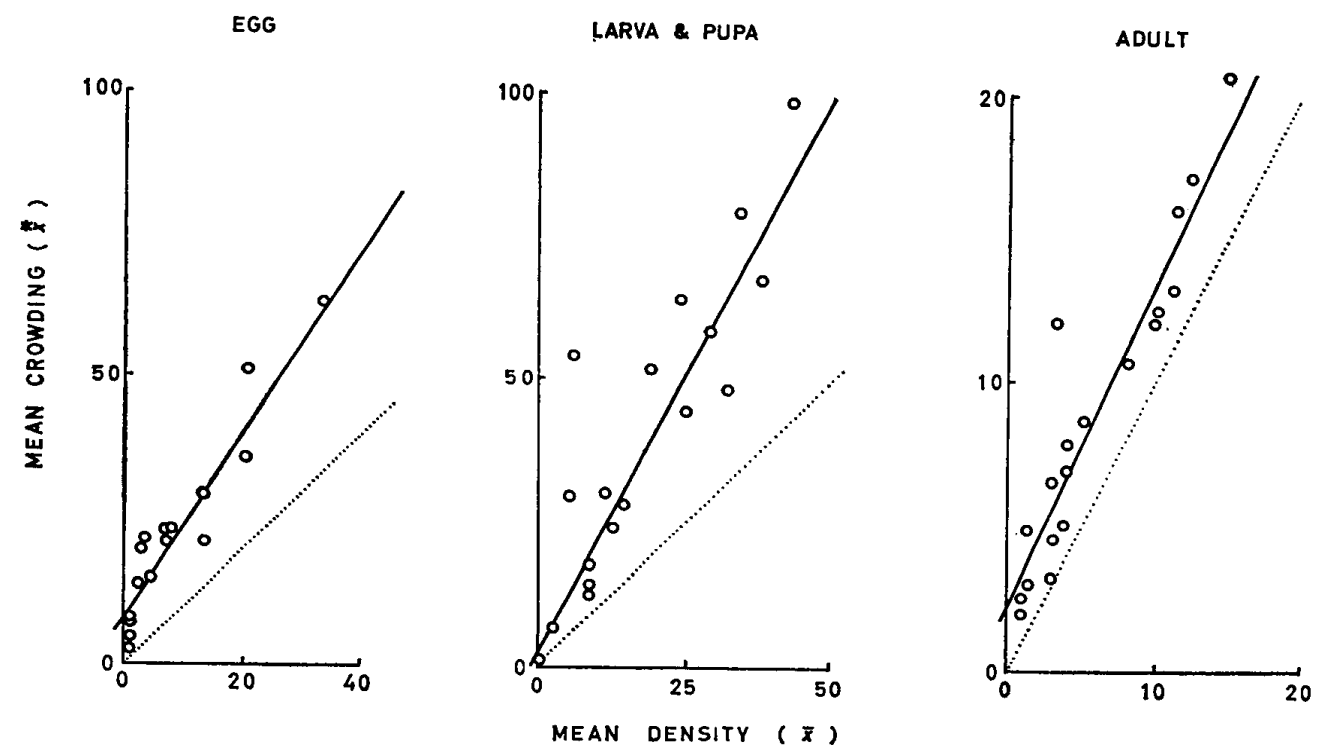

Fig. 1 Relation of mean crowding $\stackrel{*}{x})$ to mean density $(\bar{x})$ in each stage of the mosquito, Aedes albopictus in the cemetery

The $\alpha$ and $\beta$ values of the linear regression, $\stackrel{*}{x}=\alpha+\beta \bar{x}$, are summarized in Table 1, together with $r^{2}$ values indicating the goodness of fit to the regressions. Dotted lines indicated the regressions for the Poisson distribution. 
Table 1 The $\alpha, \beta$ and $r^{2}$ values in the regression, $\stackrel{*}{x}=\alpha+\beta \bar{x}$, of each stage of Aedes albopictus

\begin{tabular}{|c|c|c|c|}
\hline Stage & $\alpha$ & $\beta$ & $r^{2}$ \\
\hline Egg & 7.950 & 1.633 & 0.899 \\
\hline \multicolumn{4}{|l|}{ Larva \& pupa } \\
\hline 1st instar & 0.343 & 2.853 & 0.944 \\
\hline 2nd $\quad 11$ & 0.336 & 3.087 & 0.981 \\
\hline $3 \mathrm{rd} \quad \prime \prime$ & 2.718 & 3.127 & 0.951 \\
\hline 4 th $\quad \prime \prime$ & 2.993 & 2.184 & 0.791 \\
\hline Pupa & -1.130 & 3.174 & 0.997 \\
\hline Total & 2.606 & 1.952 & 0.874 \\
\hline Adult & 2.349 & 1.138 & 0.883 \\
\hline
\end{tabular}

Table 1. Dotted lines in Fig. 1 show expectations obtained from Poisson (random) distribution $(\alpha=0, \beta=1)$. The fitness to the linear regression is expressed by the coefficient of determination $r^{2}$ in Table 1.

We can see that linear regression $\stackrel{*}{x}=\alpha+$ $\beta \bar{x}$ may be fitted well to the observed relations as shown by $r^{2}=0.899$ for egg, 0.874 for larval and pupal and 0.883 for imaginal populations (Table 1).

From the positive $\alpha$ values thus obtained $(2.349-7.950)$, it may be suggested that a group of several individuals is the basic component of the distribution, and the $\beta$ values larger than unity $(1.138-1.952)$ indicate that such small groups of several individuals seem to distribute aggregatively over the cemetery area; but the value for adult is considerably nearer to unity, suggesting that the imaginal population distributes less aggregatively than the immature populations.

For analyzing the seasonal fluctuation of such an aggregatively distributed population, the raw data of individual counts should be transformed in such a way that the variance can be stabilized and the variate frequency distribution can be normalized. For this purpose, Iwao and Kuno (1968) presented an equation

$$
\begin{aligned}
z & =\sin h^{-1} \sqrt{\frac{\beta-1}{\alpha+1} x}=\log e\left(\sqrt{\frac{\beta-1}{\alpha+1} x}\right. \\
& \left.+\sqrt{\frac{\beta-1}{\alpha+1} x+1}\right)
\end{aligned}
$$

when $\alpha>-1, \beta>1$.

This transformation, however, is cumber- some when $\alpha, \beta$ values differ among different populations. From the standpoint of practical usefulness, a nonparametric transformation $y=\log (x+1) \quad$ (Williams, 1937) proved to be suitable to such requirements. The efficiencies of stabilizing variance and normalizing variate distribution are compared below between the above two transformations.

Figure 2 gives an example of graphical representation of such comparisons for the larval (pupal) stage, which shows the maximum contagiousness among all the three stages $(\beta=1.952$ in Table 1$)$. The efficiency of stabilizing variance is compared by the regression coefficient of the standard deviation-mean number relation, and the normalizing efficiency by the skewness of the variate frequency distribution. As seen from Fig. $2 \mathrm{~A}$, the two transformations can reduce the regression coefficient $(b)$ from the order of 0.9 to 0.1 , namely, the extent to which the variance is affected by a change of the mean number of individuals can be diminished conspicuously.

The skewness $(S k)$ of the variate frequency distribution is shown in Fig. $2 \mathrm{~B}$, together with the arithmetic means (solid triangles) indicating the central tendency of the means in the distribution ranges. The figure shows clearly that the skewness, which is 0 in the normal distribution, considerably approximates to 0 from 2.406 in the non-transformed distribution, and that the arithmetic mean comes near to center of the distribution range. The regression coefficient and the skewness for all the stages are compared between the two transformation methods in Table 2.

In the table is also summarized a result of the Bartlett's stability test of variance, which gives the $\chi^{2}$ values for the significance test by the following equation

$$
\begin{aligned}
\chi^{2}= & \frac{1}{c}\left\{\left(\sum \phi_{i}\right) \log e V-\sum \phi_{i} \log e u_{i}{ }^{2}\right\} \\
c & =1+\frac{1}{3(k-1)}\left\{\left(\sum \frac{1}{\phi_{i}}\right)-\frac{1}{\sum \phi_{i}}\right\}, \\
V & =\frac{\sum S i}{\sum} \phi_{i}
\end{aligned}
$$

where $\phi_{i}$ is degree of freedom, $u_{i}^{2}$ unbiased estimate of variance, $S_{i}$ sum of squares of deviations and $k$ number of sets of data 


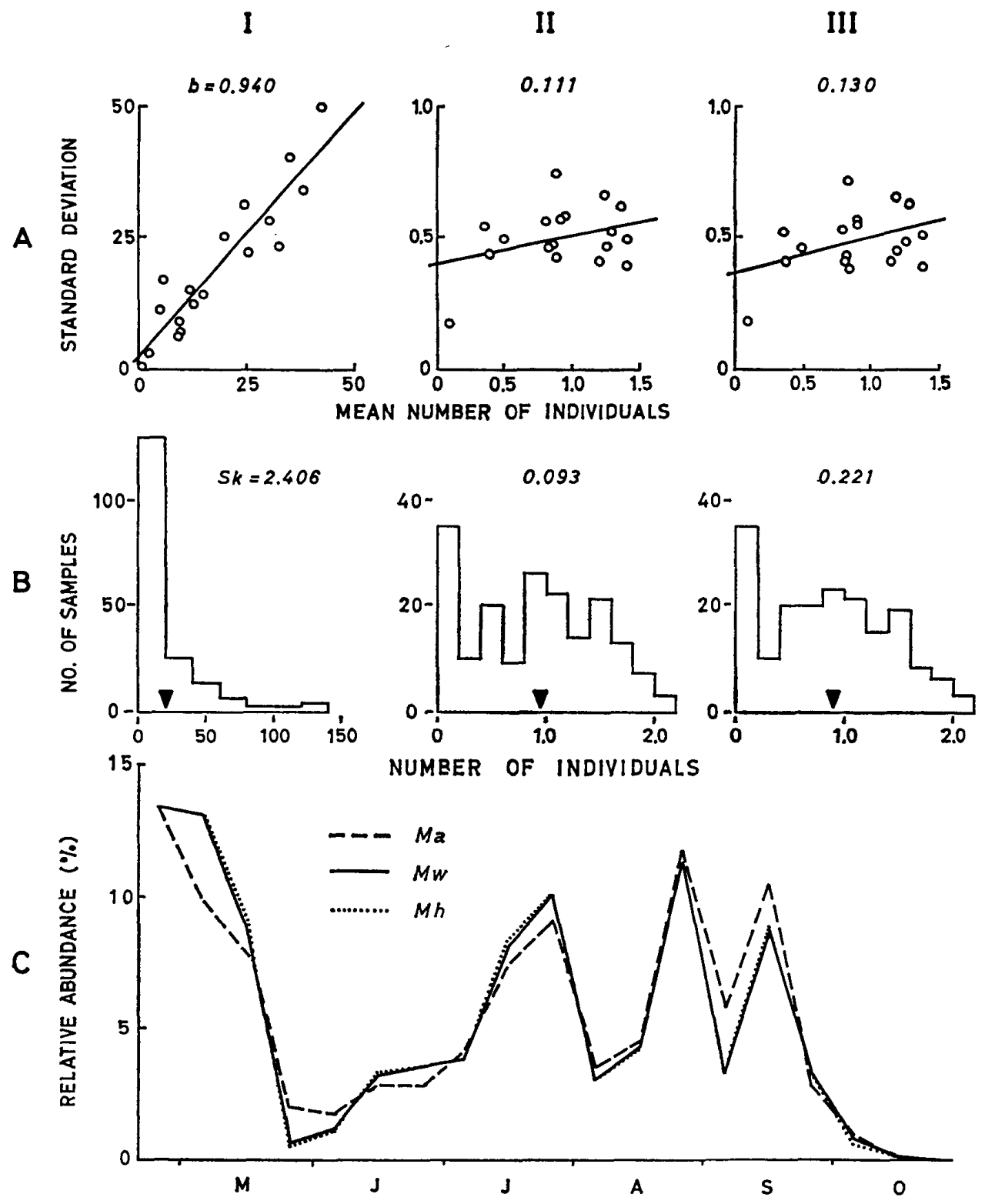

Fig. 2 Comparison of two transformation methods in efficiencies of stabilizing variance (A) and normalizing variate frequency distribution (B) (data for larval and pupal population)
I : no transformation
II : $y=\log (x+1)$
III : $z=\sin \mathrm{h}^{-1} \sqrt{\frac{\beta-1}{\alpha+1} x}$
$b$ : regression coefficient $S k$ : skewness
$\nabla$ : arithmetic mean

The $b$ and $S k$ values for all the stages are listed in Table 2. Population fluctuation curves (C) are based on the three different treatments of individual counts: (1) $M a=$ the arithmetic mean $(\bar{x})$ of non-transformed counts $(x),(2) M w=$ the Williams' mean (=antilog $\bar{y}-1$ ) derived from log $(x+1)$-transformed counts $(y)$, and (3) $M h=$ the restored value of the arithmetic mean $(\bar{z})$ of the $\sin h^{-1} \sqrt{\frac{\beta-1}{\alpha+1}} x$-transformed counts $(z)$.

Notice the closeness between the $M w$ and $M h$ curves. 
Table 2 Comparison of two transformation methods in efficiencies of stabilizing variance and normalizing variate frequency distribution

\begin{tabular}{|c|c|c|c|c|}
\hline Index & $\begin{array}{l}\text { Transforma- } \\
\text { tion* }\end{array}$ & Egg & Larva \& pupa & Adult \\
\hline \multirow{3}{*}{$\begin{array}{l}\text { Regression } \\
\text { coefficient }(b)\end{array}$} & I & 0.878 & 0.940 & 0.516 \\
\hline & II & 0.295 & 0.111 & -0.002 \\
\hline & III & 0.314 & 0.130 & 0.040 \\
\hline \multirow{3}{*}{ Skewness $(S k)$} & $\mathrm{I}$ & 2.617 & 2.406 & 1.434 \\
\hline & $\Pi$ & 0.688 & 0.093 & 0.021 \\
\hline & $\mathrm{mI}$ & 0.923 & 0.221 & 0.100 \\
\hline \multirow{3}{*}{$\begin{array}{l}\text { Chi-square }\left(\chi^{2}\right) \\
\text { and probability** }\end{array}$} & I & $161.24(\quad P<0.001)$ & $145.27(\quad P<0.001)$ & $92.18(\quad P<0.001)$ \\
\hline & II & $26.75(0.02<P<0.05)$ & $20.75(0.20<P<0.30)$ & $16.35(0.50<P<0.70)$ \\
\hline & III & $29.68(0.01<P<0.02)$ & $20.79(0.20<P<0.30)$ & $15.84(0.50<P<0.70)$ \\
\hline
\end{tabular}

* I : no transformation $\quad \mathrm{II}: y=\log (x+1) \quad \mathrm{III}: z=\sin ^{-1} \sqrt{\frac{\beta-1}{\alpha+1} x}$.

** After Bartlett's method for stability test of variance.

One example of graphical representation is shown in Fig. 2 for the larval and pupal stage which has the maximum contagiousness.

$(i=1,2, \cdots, k) . \quad$ (Okamatsu (1968) was consulted for practical calculation).

From the $b$ and $S k$ values in Table 2 , it is clear that both of the two transformations are efficient in stabilizing variance and normalizing variate distribution, but $y=\log$ $(x+1)$ transformation is somewhat better than $z=\sin h^{-1} \sqrt{\frac{\beta-1}{\alpha+1} x}$. And from the $\chi^{2}$ values in the table we accept the stability of the variance of thus transformed data sets at $5 \%$ or $1 \%$ level of significance.

Figure $2 \mathrm{C}$ indicates the population fluctuation curves of the larval (pupal) stage obtained by three different treatments of individual counts: (1) $M a=$ the arithmetic mean $\bar{x}$ of the non-transformed counts, (2) $M w=$ the Williams' mean, or antilog $\bar{y}-1$, derived from the $\log (x+1)$-transformed counts, and (3) $M h=$ the restored value of the arithmetic mean $\bar{z}$ of $\sin h^{-1} \sqrt{\frac{\beta-1}{\alpha+1} x-}$ transformed counts. As will be seen from the figure, the fluctuation curve based on the $M w$ values (solid line) almost coincides with that based on the $M h$ values (dotted line). Similar results were obtained also in the egg and imaginal stages. We can conclude from these results that the log $(x+1)$ transformation is as useful as the $\sin$ $\mathrm{h}^{-1} \sqrt{\frac{\beta-1}{\alpha+1} x}$ for preparing the fluctuation curves of the aggregatively distributed mosquito populations.

\section{DISCUSSION}

In preceeding papers (Makiya, 1973, 1975), the distribution pattern of mosquito populations was analyzed using the variance-mean density relation and contagiousness of the populations was estimated by a common parameter $k$ of the negative binomial distribution fitted to the field data after BlissOwen's method. This method, however, can be fitted only to the aggregative population whose basic component is a single individual, and is troublesome in calculating the $k$ value.

In the present report, the mean crowdingmean density relation, $\stackrel{*}{m}=\alpha+\beta m$, was applied to the field data in order to analyze the distribution pattern of the mosquito population. This method was developed by Lloyd (1967) and Iwao (1968), and easy to calculate the parameters $\alpha$ and $\beta$, by the least square method. This relation can widely be fitted to various distribution patterns of biological populations: for example, the negative binomial distribution with a common $k$ can be expressed by this $\stackrel{*}{m}$-on- $m$ 
regression with $\alpha=0$ and $\beta=1+1 / k$.

In case of Aedes albopictus, $\stackrel{*}{m-m}$ relation was fitted well to the observed counts of each stage of the mosquito, and the parameters were estimated as $\alpha>0$ and $\beta>1$, indicating that groups of several individuals seemed to distribute aggregatively over the cemetery area.

Among several transformation methods thus far proposed, two formulae were compared from the viewpoint of efficiencies of stabilizing variance and normalizing variate frequency distribution: one is parametric transformation based on the $\alpha, \beta$

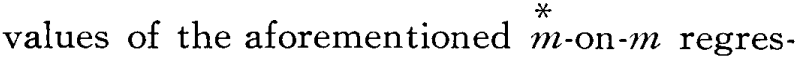
sion and the other non-parametric $\log (x+1)$. The result indicates that the non-parametric $\log (x+1)$ transformation is as useful as the parametric one, and this log-transformation proved of great use also in comparison with another parametric transformations $\log (x+$ $k / 2$ ), $V \bar{k} \sin \mathrm{h}^{-1} \sqrt{k x}$ based on the $k$ value of the negative binomial (Makiya, 1975).

From these comparisons, we can conclude that this simple transformation may be very useful in interpreting the fluctuation of aggregative populations.

\section{ACKNOWLEDGEMENTS}

The author wishes to express his sincere thanks to Prof. N. Kumada for his critical reading of the manuscript.

\section{REFERENCES}

Anscombe, F. J. (1948): The transformation of Poisson, binomial and negative binomial data. Biometrika, 35 : 246-254.

Beall, G. (1942): The transformation of data from entomological field experiments so that the analysis of variance becomes applicable. Biometrika, 32 : 243-262.

Iwao, S. (1968): A new regression method for analyzing the aggregation pattern of animal populations. Res. Popul. Ecol., 10 : 1-20.

Iwao, S. and E. Kuno (1968): Use of the regression of mean crowing on mean density for estimating sample size and the transformation of data for the analysis of variance. Res. Popul. Ecol., 10 : 210-214.

Lloyd, M. (1967): 'Mean crowding'. J. Anim. Ecol., 36 : 1-30.

Makiya, K. (1973): Population dynamics of mosquitoes in Nagoya district. A. Larval population of Aedes albopictus (Skuse) in a cemetery of Nagoya City in 1967. Jap. J. Sanit. Zool., 24 (2): 155-164 (in Japanese, English summary).

Makiya, K. (1975) : Some considerations on the fluctuation of population size of mosquitoes observed with light traps. Jap. J. Sanit. Zool., $26(2 \cdot 3)$ : 73-82 (in Japanese, English summary). Okamatsu, M (1968): Notes on stochastics. 18th ed., Ohm-sha, Tokyo (in Japanese).

Williams, C. B. (1937): The use of logarithms in the interpretation of certain entomological problems. Ann. App. Biol., 24: 404-414.

\section{摘 \\ ヒトスジシマカの分布様式および $\log (x+1)$ 変換法の実用性に関する考察}

1972 年名古屋市の 1 共同墓地におけるヒトスジシマ 力卵・幼虫 (蛹) - 成虫個体群の分布様式について，いく つかの考察を行なった。

1）各発育期個体群の分布様式を知るために，個体数 の観測データに平均こみあい度 $(\stackrel{*}{m})$-平均密度 $(m)$ 回 帰， $\stackrel{*}{m}=\alpha+\beta m$ を適用した。 その結果, 各発育期とも 数個体からなるコロニーが墓地全体にわたって集中的に 分布するものと思われた (Fig. 1, Table 1).

2) 集中分布をする個体数観測データの変換法のう ち, $y=\log (x+1)$ と $z=\operatorname{sin~} \mathrm{h}^{-1} \sqrt{\frac{\beta-1}{\alpha+1} x}$ の 2 式につ いて, 分散の安定化と変量頻度分布の 2 点から変換の効 率を比較した。 その結果，前式はパラメーターを用いな い簡単なものであるが，後式に劣らぬ効率の良い変換法 であることがわかった（Fig. 2, Table 2). 